not used, but attention has been directed toward varying the quantity of the explosive mixture, and certain English makers use a system of throttling. It is obvious that variable admission means also variable compression, and this interferes with the prompt ignition of the mixture. The most recent improvements have involved mechanism, by means of which the variable admission of the constant mixture has been combined with an additional admission of air so that constant compression may be obtained.-Engineering Times.

$$
\text { [Continued from SUPrLem RNT No. 1584, page 25378.] }
$$

RESERVOIR, FOUNTAIN, AND STYLOGRAPHIC PENS.-VI.*

By James P. Maginnis, A.M.Inst.C.E., M.Inst.Mech.E FOUNTAIN PENS.

ANOTHER pen with a flexible rubber ink reservoir was patented by Reschke \& Leutner, in 1886 (4368), and is shown in section in Fig. 129. The tubular holder or casing contains a reservoir, $F$, of India rubber or other elastic material. This is attached at its upper end to a screwed rod, $B$, and a knob, $A$, by which it may be twisted to expel ink or air. A stud or pin, $D$, is place at the side, and the reservoir, $F$, may be compresse by this means. Ink is delivered to the nib, $N$, through the passage, $G$, to $C$. The tongue, $K$, acts as a spring to grip the nib. long feed bar or stem, grooved along its entire length, is attached to the back of the diaphragm, $B$. This feed bar is so bent that it may slide stiffly into the reservoir, thus enabling the holder to be refilled, without the necessity of entirely removing it. A minute opening in the diaphragm, $B$, admits air to the ink reservoir.

In the patent of Brown, of 1886 (15638), the inventor has turned his special attention to the feed arrange ments, and the drawings shown in Fig. 133 give some idea of his various forms of feed bars. The invento has a preference for an elliptical or triangular opening in the point section, the feed bar itself being generally triangular in section, and more or less grooved to form air and ink ducts. In $A$ the feed bar is pyramidal with a deep V-shaped groove, and a rearward extension. In $B$, it is grooved transversely. In either case the feed bar is placed over the nib, having an edge or apex in contact with it, as shown in $C$, the nib resting on the seating shown in D. The surface of this seating does not fit closely to the nib, in order that a void may exist to hold an additional supply of ink.

Palmer \& Richter in their patent of 1886 (16738) claim improvements in feed bars. The reservoir is of ordinary construction. The point section is here shown in Fig. 134, provided with a beak, $D$, fitting over the nib, $P$. The feed bar, $E$, is hollow at $G$, with a channel extending the whole length of its upper sur-
In Blair's pen of 1887 (5995), a part section of which is shown in Fig. 137, a corrugate tube, $B$, has a rubber tube, $R$, pushed in at the rear end to form a tight joint with the holder, $A$, and a second corrugated tube, $C$, inserted at the front end of the tube, $B$, provides a holder for the nib, $N$. The ink travels along the metal strip, which is held in position by the absorbent wooden rod, $T$. This rod, $T$, serves also to absorb any excess of ink in the passage when the pen is out of use. In Fig. 138, W. J. Thomas, 1887 (8271), it will be seen that the reservoir, $A$, is perforated by an opening, $B$, at an inclination from the axis of the pen. Into this is screwed a short tube, $P$, through which the ink flows to the nib. This tube has a tapering bore, as shown in the section at $K$, and a piece of cane is inserted therein. The nib is held in position by a bent plate, neither of which is shown on the drawing. The object in placing the feed tube at the angle shown is to prevent leakage when the pen is placed on a desk, and the holder is so weighted as to automatically keep the pen in the position indicated. Air is admitted at the top of the reservoir.

Again, in Fig. 139, is a flexible reservoir, patented by W. E. Burton, in August, 1887 (11728). A short rubber tube is fixed inside the outer protecting tube, $A$, and may be operated from the exterior by the stud and plate, $B$. Pressure on the stud compresses the flexible tube and forces a small quantity of ink to the

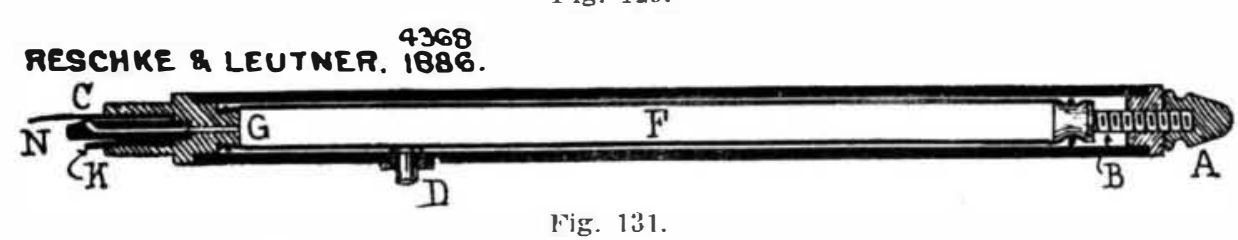

RIDGE. $\begin{array}{r}9346 \\ 1886 .\end{array}$

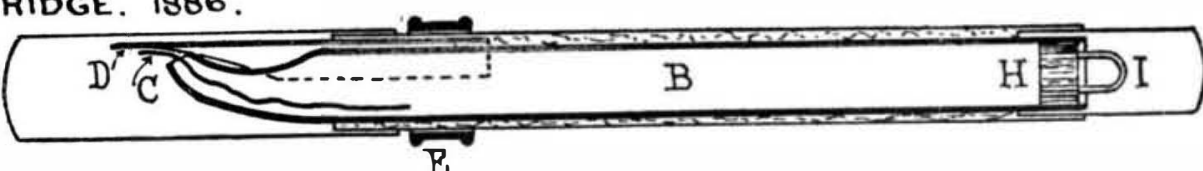

SACKETT. 10827

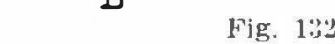

Fig. 132

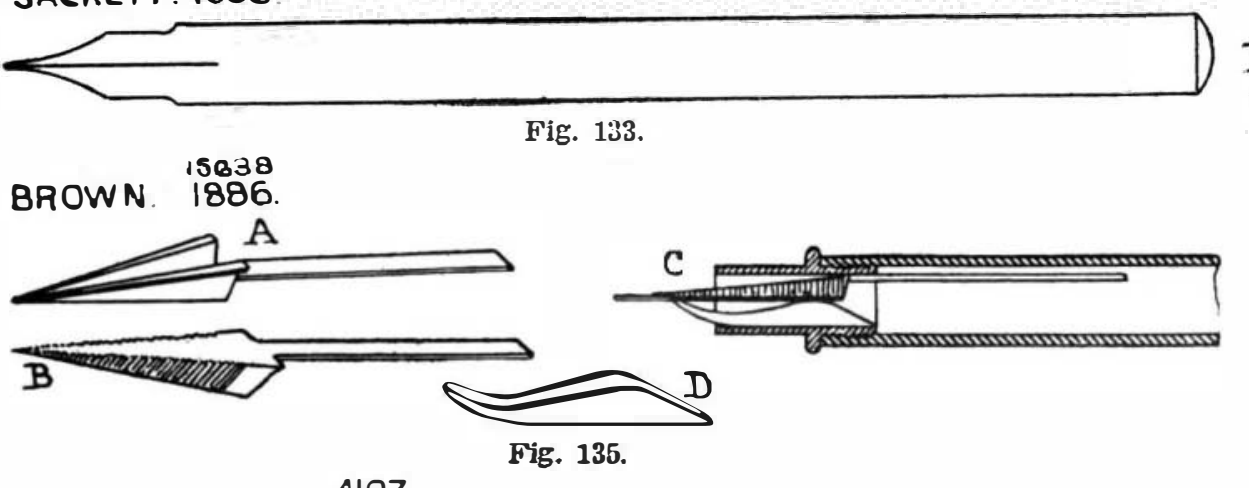

SACKETT. $\begin{array}{r}12323 \\ 1886\end{array}$

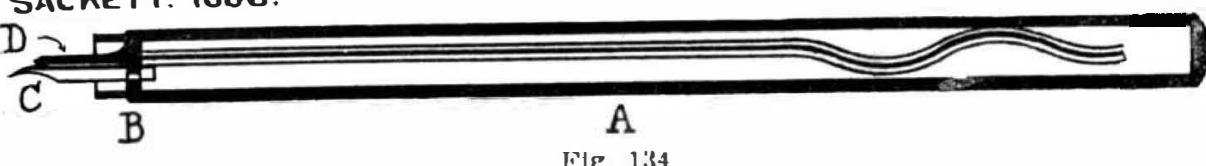

PALMER \& RICHTER. 1886
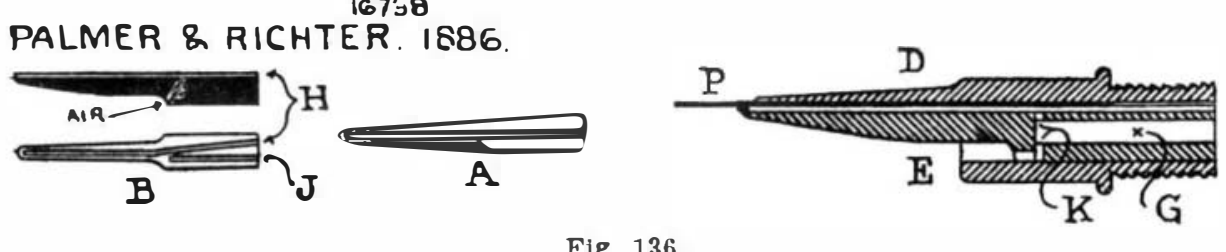

SCHMACKELSEN. 18107

HARRISON \& MARA 4587
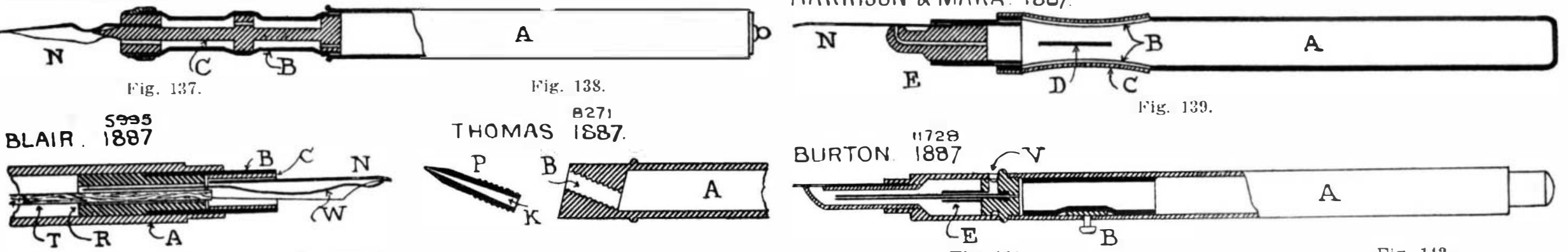

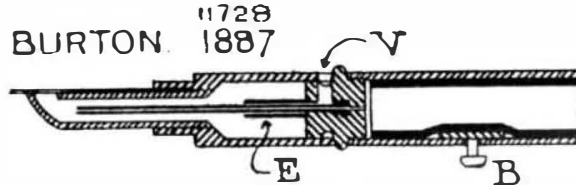

E

Fig. 141

HOMMEL $\begin{aligned} & 7168 \\ & 1888\end{aligned}$

Fig. 136.

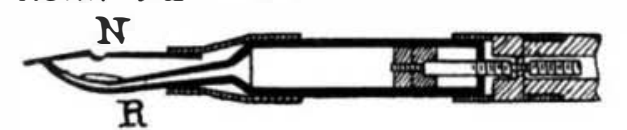

Fig. 143.

A

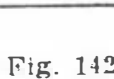

JONES. $\begin{array}{r}7293 \\ 1888\end{array}$

DE LAMBERT. ${ }^{15625}$
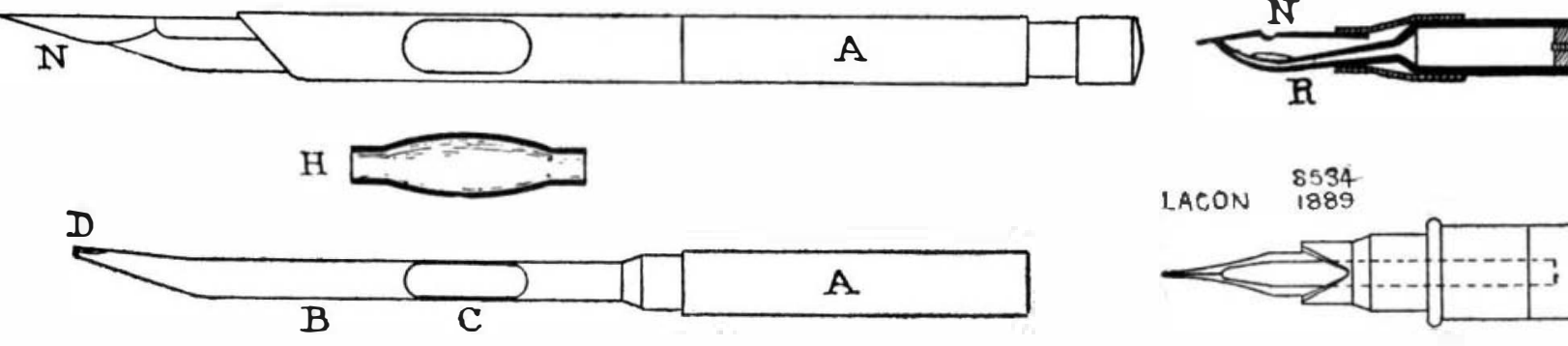

In Ridge's pen of 1886 (9346), shown in Fig. 130 the reservoir, $B$, is made of glass, drawn out at one end to a point through which a wick, $C$, project against the nib, $D$. A movable plug, $H$, closes th upper end of the reservoir, and this is provided a shown with a wire loop, $\boldsymbol{I}$. This plug may be pushe down the reservoir to the lower end, and raised to th position shown by a hooked rod, and thus the pen may be charged with ink. To protect the glass tube it is covered with an outer case, into which it is fitted by suitable packing. A sliding ring, $E$, is provided as a means of holding the nib in position.

Mr. G. H. Sackett's patent, August, 1886 (10827) shown in Fig. 131, is an exaggerated barrel pen, made of metal, closed at its upper end and terminating at it lower end in a writing nib having an extra long slit. The lower end of the tube is closed also, that any in contained in it can only escape through the slit, to the point of the nib, and then only during the operation of writing.

In Sackett's patent of 1886 (12323), shown in Fig. 132 , the tubular reservoir, $A$, is closed at one encl, an provided at the other with a movable diaphragm, $B$, having a crescent-shaped slit for receiving the nib, $O$, and for allowing the proper flow of ink. A tongue, $D$, is attached so as to rest on the back of the nib, and face which comes in contact with the nib, $P$. A enters is provided for the passage of the aity, $G$. A $A$ is shown a openings at $K$, into the cavity, $G$. A or groove along its upper surface. A modified form of leed bar is shown at $B$, the upper view being in section. In this, ink travels along the groove, $H$, to the nib, while air enters at the point indicated by the arrow, and passes along the shorter groove, $J$.

Fig. 135 is the invention of J. Schmackelsen in 1887 (4107). This is a combination of both rigid and flexible ink reservoir. The reservoir, $A$, is prolonged by the addition of a flexible tube, $B$, stiffened by a rod, $C$, provided with bosses supporting the flexible tube at intervals. Ink passages are formed in the bosses as shown. A ring at the end forms a termination to the flexible tube, and supports the front end of the rod, $C$ thus forming a holder to contain the nib, $N$. The rod, $C$, also carries ink to the nib. The flexible tube collapses, more or less, with the pressure of the fingers of the writer, and ink is thus forced forward.

Another flexible ink reservoir is here shown in Fig. 136, Harrison \& Mara, 1887 (4575). The tubular holder, $A$, is of metal, and is provided with openings, $B$. These openings are covered with India rubber or some other elastic material, $C$, while the sides are stiffened by a partition, $D$. A section of the feed bar, $E$, shows the method of delivering ink to the nib. $N$. lower end of the pen, as shown, while air is admitted at $V$. On reversing the pen, the ink from the pen flows backward to the chamber $E$.

The flexible ink reservoir is again shown in Fig. 140, patented by de Lambert in 1887 (15625). The tubes, $A, B$, form the reservoir. In $B$ is a slot or opening, $C$, into which a small sponge is inserted, and a flexible rubber sleeve, $H$, is slipped over this opening. Another metal tube is placed over this, as shown in the drawing of the complete pen, and this also has a slot or opening through which may be seen the rubber sleeve, $H$. Pressure with the finger upon the rubber sleeve forces ink through the opening at $D$ to the nib, $N$

In Fig. 141 we have Hommel's patent of 1888 (7166), being another instance of the introduction of a mechanical arrangement for drawing in or discharging ink by means of a piston. Ink is supplied through the fine tube, $R$, to the nib, $N$.

In the invention of $\mathrm{F}$. H. Jones (7293) May, 1888, the reservoir consists of a glass tube, drawn to a fine point at one end, and covered at the other after the manner of a drum with some elastic material, on press. ing which ink is forced out through the point to the nib. The reservoir is filled by

Fig. 142 shows a self-acting device by the same in ventor for closing the ink outlet when the pen is re- 
versed. The disk, $C$, falls down upon the orifice; $W$ is a weight provided to insure its doing so.

There appears to be nothing particularly striking in this pen (W. Guthrie, 1888, 10934). In using the pen, it is first held with the point upward, and then inverted, when a drop of ink flows to the nib. When this is used the pen is again held point upward, and so on In the invention of E. Lacon, in 1889 (8534), th reservoir is of glass or of other transparent materia and the other protecting (uver is slotted, so that the quantity of ink within may be readily seen. Fig. 14 shows the general appearance of the pen. A valve is provided for controlling the admission of air. A rin is placed on the upper end, capable of sliding up an down for the purpose of opening or closing the ai inlet valve, $V$.

In Fry's patent of 1889 (10435), the reservoir is closed by a plug, and the feed bar is perforated by minute holes, so formed that the edges of the openin are in contact with the nib. For the purpose of regulating the flow of ink into the feed tube a plug is provided, which may be screwed down to close completely the passage to the feed tube. When unscrewed the in flows through the orifice.

Fig. 144 shows Pickhardt's pen of 1890 (3:3), the res ervoir of which is made of glass drawn to a fine point. Within the tapering point is placed a tube, $C$, of gauze or woven asbestos, the end of which is in contact wit the under side of the nib, $N$. A modification is show in Fig. 145, where the point or feed tube, $A$, is of vulcanite, and, instead of the gauze tube, $C$, of Fig. 144, tongue is cut from the nib, $N$, which is in contact with, or just enters, the ink outlet.

H. Pearse designed a pen in 1890 (59), which instea of having the familiar piston and its rod is fitted with nib. A folded wire, $G$, passes from the feed tube to the reservoir

The Eagle Pencil Company, in 1890 (15053), describe a pen in which the nib is held between the barrel an the ink conductor. At the rear end of the barrel is a India-rubber tube connecting it to the reservoir. The ink conductor or feed bar has one or more longitudina grooves, and a saw-cut under the point renders it more flexible.

In Hyde's patent of 1890 (6094) the feed tube is cut with a number of transverse slits to render it flexible. Fig. 148 shows a longitudinal section of the nib socket, which is formed with openings for the nib, $D$ (as shown in cross section), a feed tube, $G$, and an opening, $E$, for the admission of air. A longitudinal slit is provided immediately over the nib for the delivery of ink.

The reservoir in Robinson's patent of 1890 (8629) shown in Fig. 149, is provided with a plug, $B$, adapted to hold the nib, $D$. This plug is provided with a groove above the nib, and in which is placed a wire or strip, $F$, flattened at the end in contact with the nib. A filling piece is placed in the groove, so that ink flows only in the narrow space between the wire and the surrounding walls.

In Shaw's patent of 1891 (6398), the reservoir is closed at one end, and has two openings at the othe for the inlet of air, and for the outlet of ink, respeclively. The lower, or penholder part, screws on the reservoir, and has openings corresponding to the inlet and outlet openings. It is hollowed out to receive the nib part. The nib is covered with a plate, between which and the nib the ink flows, air entering at an opening provided.

In the invention of Krulis \& Adutt of 1891 (3523) serves as a feeder for the ink from the reservoir to the nib, small passages (not shown on the drawing) being formed at its side for the purpose.

In Fig. 152, 1892 (2128) is shown the feed arrangement of Walke \& Davis. Air tubes, $E$ and $F$, are fitted within the point section, $B$. The tube, $E$, is wide at the upper part to fit the bore, $B$, and of less diameter at the lower part to receive the nib and ink conductor, $D$. A groove, $H$, is formed in the tube, $E$, to allow ink to flow to the conductor. Within the tube, $E$, is fitted the adjustable tube, $F$, having a small bore for the gradual dmission of air to the reservoir

A piston of peculiar construction is used in the pen shown in Fig. 153 (3325, Blake, Pratt \& Taylor, 1892). It is formed of a tube, $B$, having a longitudinal slit or saw cut, and filled with India rubber to render it elastic and form a tightly-fitting joint. Attached to the piston is a casing, $G$, which slides with the piston. The feed tube, $C$, is fitted with a valve, $V$, to regulate the ink flow and with a mid-feather, $F$, to feed the ink to the nib.

In Fig. 154 L. Lowenstein, 1892 (17393), the tube, $A$, is formed with internal screw threads at each end. In the lower end two plugs, $B$ and $C$, are screwed. One plug, $B$, has two holes, and a conical projecting portion, $E$, which enters the opening in the plug, $C$. The position of the lower plug, $C$, can be altered by means of a milled head, $\boldsymbol{\bullet}$, and the amount of opening thereby regulated. Ink flows to the nib, $N$, through a passage provided. An air inlet is arranged at the upper end of the reservoir, so that when the cap, $T$, is slightly uinscrewed air may enter through the channels formed in the plug, $P$. To fill the pen with ink, the plug, $P$, is in the in

In the inventien of W. Higgs, patented in December,
Fig. $1+1$

33
PICKHARDT 1890

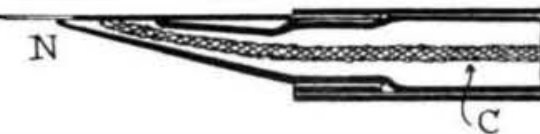

Fig. 147 .

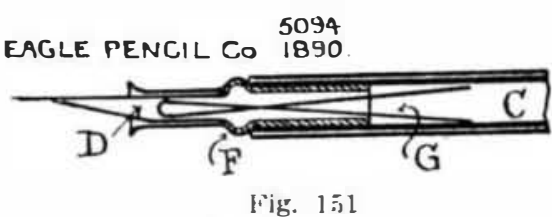

EVANS. 1892

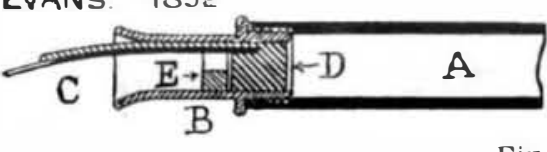

Fig. 15
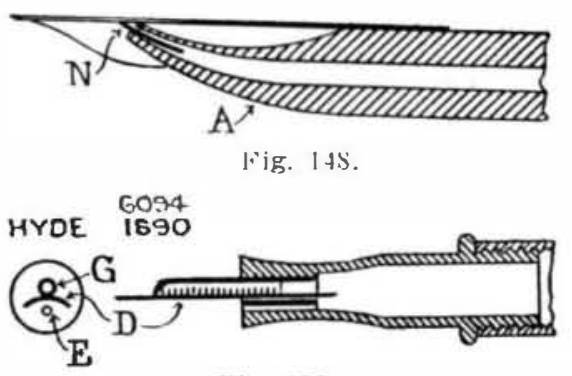

Fig. 152

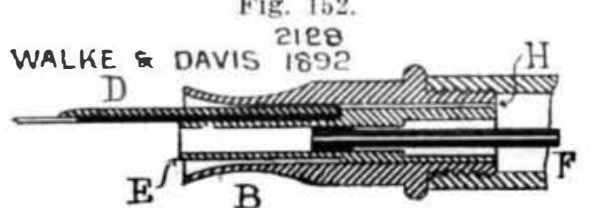

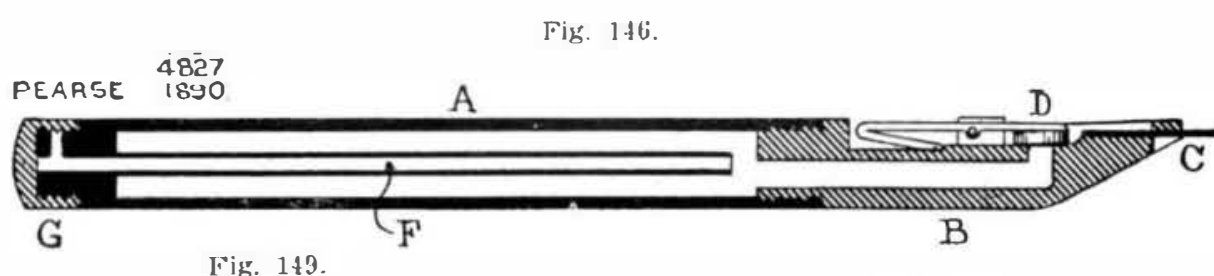

8629
1990

ROBINSON. $\quad 8629$

Fig. 150 .

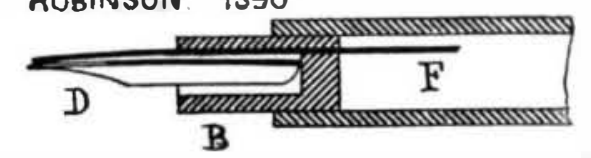

ROBINSON 1845

l.ig 153

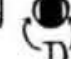

BLAKE, PLATT \& TAYLOR. 1992

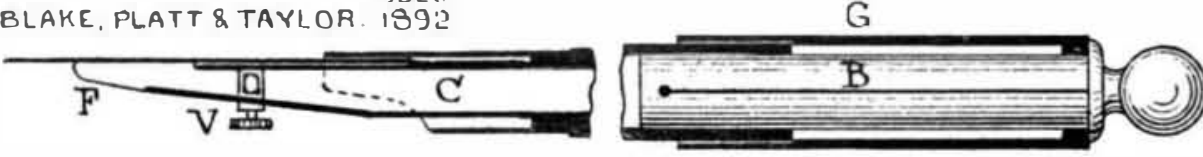

Fig. 155.

T LEARY \& CALLAHAN $\begin{array}{r}13092 \\ 1893\end{array}$

LOWENSTEIN 17393

A
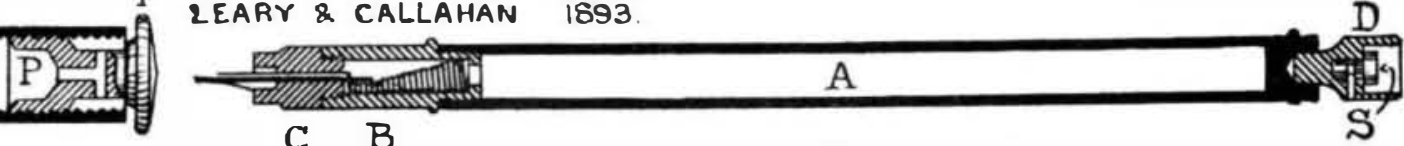

POST $\begin{array}{r}1039 \\ 1894\end{array}$
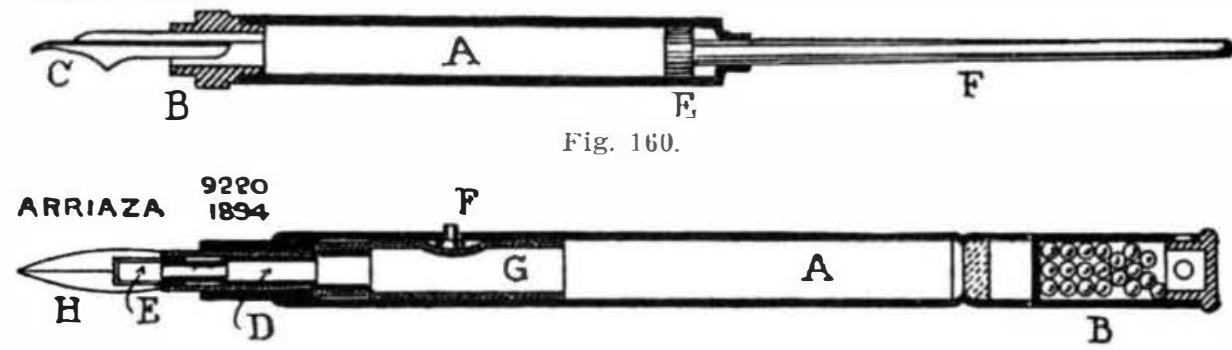

STONEHOUSE 1894

BROWNING $\begin{array}{r}5256 \\ 1894\end{array}$

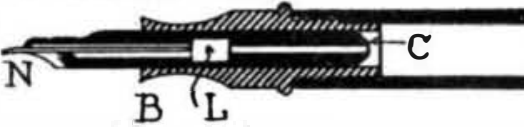

STONEHOUSE 1894

159

a plunger screwing into the reservoir for its entir enth as a means of forcing ink to the nib.

length, as a means of forcing ink to the nib.
Falconnet and others took out a patent in 1889

Falconnet and others took out a patent in 1889
(7784), for a piston type of pen, the ink being ex pelled from the reservoir by the movement of the pison. The piston has a threaded perforation, through which passes a rod, the rear end of which is secure to a cap, and as the cap is turned, so the rod is also turned, and by reason of the screw the piston is thus made to traverse the interior of the reservoir. The ink flows to the nib through a tapering tube or fee ar which is slotted under the nib.

In the invention (3252) of Hill \& Appleton, 1890 the reservoir is of gutta percha (placed within a metal tube), and is open at one end, and closed at the othe Into the open end is screwed the feed bar, which hollow, and has two small openings for the admission of air and

In F'ig. 146 Pearse's patent of 1890 (4827), the nib $C$, is carried on a part, $B$, screwing into the reservoi $A$. The outflow of ink is regulated by a valve, $D$, op erated by a lever as required. Air is admitted at the other end of the pen through a tube, $F$, which is covered by the cap, $G$, when out of use.

This pen, Fig. 147, the production of the Eagle Penci Company, 1890 (5094), is described as being formed in three parts, the reservoir, the barrel, and the feed tube. The reservoir, $C$ is connected to the barrel by an elastic tube, $F$. The feed tube is formed with swelling or shoulder, which prevents it slipping too far forward, and it is slotterl for the ink to flow to the

he ink is contained in the reservoir, and flows to the ib through a tube. This tube may be carried by the valve carried on a rod fixed to a plug fitted in the uppe end of the reservoir. An elastic rubber plug or sprin orces the plus

Mr. Robinson $(1891,14453)$ has here designed a fee bar of solid construction, formed with two flattened bar of solid construction, formed with two flattened surfaces as shown in Fig. 150, at $D$, one on either side, nib. Mrs. Robinson has kindly handed me a pen which Messrs. Harmsworth produced under the name of "Answers" pen, and the feed bar now shown appear "Answers" pen, and the feed bar now shown appears to be identical with that of this pen. It is interesting to note that the "Answers" pen was designed by $\mathrm{Mr}$. Robinson in response to Messrs. Harmsworth's offer
of a five-guinea prize for the best new invention, and of a five-guinea prize for the best new

he was successful in winning the prize.
Another pen is the invention of $\mathrm{A}$. Theodorides in Another pen is the invention of A. Theodorides in
1891 (17053). In this case the reservoir consists of 1891 (17053). In this case the reservoir consists of
an India rubber bag closed at one end, and having a an India rubber bag closed at one end, and having a
rigid bent nozzle at the other, so adapted as to be in rigid bent nozzle at the other, so adapted as to be in contact with the underside of the nib. In the oute case is an aperture through which the reservoir ma be compressed by the finger when the nib requires fresh supply of in

The feed bar shown in Fig. 151, T. W. Evans, 189 (994), is of simple construction. $A$ is the ordinary ofing a point section, $B$, screwed into it. A nib, $C$, of ordinary form, is held in grooves in the point section and further leept in place by the plug, $E$. The solid plug, $D$, with its projecting beak or tongue,
1892 (23632), the ink reservoir consists of a rubber bag contained in the body of the pen, and attached at its mouth to a cylindrical piece, and at the other end to a revolving plug. The pen is filled by twisting the plug and with it the rubber tube, so as to expel the air. On immersing the point in ink and reversing the twisting action, ink is drawn into the reservoir.

In Fig. 155 Leary \& Callahan, 1893 (13092), $A$, is the usual ink reservoir, and $B$ is the point section, having a nib holding section, $C$. The nib passes through the hole, and is attached to the spiral spring shown coiled within $B$, the end of which passes upward through an opening in the butt end of the nib, and then passes down its back, reaching to the slit. When the cap, $D$, is placed over the point, the nib impinges upon the swiveling part, $\mathbb{S}$, and is forced backward against the pressure of the feed spring, which projects the nib into the forward position when the cap is again removed. J. E. Chase, in 1893, patented a pen in which the nib is permanently attached to a rod by a rivet. The chief feature of this pen lies in the arrangement whereby the nib is made to recede when out of use

The pen shown in Fig. 156, E. Reichmann, 1893 (20699), the inventor states, is for use with any form of steel nib. The reservoir, $A$, communicates with the fexible tube, $B$, which is pressed against the nib, $F$, by means of the spring, $C$. A wire, $D$, extends from the reservoir, $A$, through the tube, $B$, and terminates at $E$, and thus conveys ink to the nib, $F$.

The body, A, of the pen shown in Fig. 157, W. Post, 1894 (1039), contains a plunger or piston, $E$, attached $n$ a rod or handle, $F$, The nib. $C$, fits into grooves in 
the point section $B$. The body, or reservoir, $A$, is nal with ink by operating the pl the rod, $F$, as one piece, but the pen as now made has a telescopic rod, which reduces the length of the complete pen.

Fig. 158 shows a section through the ink feedin (5256). Th leed bar, $C$, is formed in one piece, and fits into the tion, $B$. The nib, $N$, is held betwee backward into the ink tongues as shown, and project cates with the ink reservoir by the side ducts. Groove on the inner surfaces of the tongues communicate with the air passage, which runs centrally through the feed bar. This pen was introduced by Mr. Robinson as the "Regal."

In the feed bar shown in Fig. 159 of J. H. Stone house, patented in 1894 (5984), a central longitudinal groove extends along its upper surface next the nib either side for the passage of air. The pen is otherwise of ordinary construction.

The invention, D. Arriaza, 1894 (9220), illustrated in Fig. 160, relates to a pen in which a solution of solid ink is used to write with. The pellets of ink are lets are placed in the reservoir, $A$, into which water is introduced. The internal reservoir, $G$, is of flexible rubber tubing, and by exerting a slight pressure on the stud, $F$, ink is forced along the tubes, $D$, and an ink conductor to the nib, $H$. When the pen is out of use the cap, $E$, is pushed backward so as to cover the opening in the feed tube, $D$

(To be continued.)

\section{MANUFACTURE OF GUN-COTTON.}

For the production of a bigh-grade gun-cotton, it is very important that the cotton used should approach as near as possible to pure cellulose. The waste from cotton mills, thoroughly purified, is usually employed. $\Lambda$ fter careful chemical examination has been made to the cotton waste is picked over by hand to remove such impurities as wood, cardboard, string, etc. The cotton is then passed through the "teasing machine," which opens out all knots and lumps, thereby reducing it to a state more suitable for the acid treatment and exposing to view any foreign substances which may exposing to view any foreign substances which may
have escaped notice in the previous picking. The cot have escaped notice in the previous picking. The cot-
ton is then dried. When perfectly dry, it is removed ton is then dried. When perfectly dry, it is removed
to air-tight iron cases, in which it is allowed to cool. The iron cases are taken to the dipping houses, and the cotton waste weighed into small portions which are cotton waste weighed into small portions which are then transferred as rapidly as possible to the mixed
acids, allowed to remain a few minutes, then removed acids, allowed to remain a few minutes, then removed
to the grating and the excess of acid squeezed out. The cotton now containing about ten times its weight The cotton now containing about ten times its weight
of acid is lace in an earthenware pot and transferred to the steeping pits, where it is allowed to remain for to the steeping pits, where it is allowed to remain for
twenty-four hours, a low temperature being main tained by a stream of cold water.

The cotton is now wholly converted into nitro-cellulose. The superfluous acid is next removed by a centrifugal extractor, after which the gun-cotton is taken out of the machine and immediately immersed in a arge volume of water, and thoroughly washed unt it shows no acid reaction. The moisture is then
wrung out and the gun-cotton is conveyed by tramway to the boiling vats, where it undergoes several boilings by means of steam. When the "heat test" shows that ay means of steam. When the "heat test" shows that gun-cotton is removed to a beating engine, and reduced to a very fine state of division. When this process is completed the pulp is run by gravity along wooden shoots, provided with "grit traps" and electro-magnets, which catch any traces of sand, iron, etc., into large "poachers" in which the gun-cotton is continuously agitated, together with a large quantity of water. In this way it is thoroughly washed and a blend made of large quantity of gun-cotton.

large quantity of gun-cotton.
Soluble Gun-Corton.- Soluble gun-cotton is made on the same lines as above, except that greater attention has to be paid to the physical condition of the cotto used, and to the temperature and strength of acid mixure, etc.

The term "soluble" usually implies that the gun cotton is dissolved by a mixture of ethyl-ether and
ethyl-alcohol, two parts of the former to one of the ethyl-alcohol, two parts of the former to one of the latter being the proportions which yield the best sol
vent action. The classification of nitro-celluloses ac cording to their solubility in ether-alcohol is misleading, except when the nitrogen contents are also quoted. The number of solvents for gun-cotton which hav at various times been propesed is very large. Among
the more important may be mentioned the following: the more important may be mentioned the following:
Alcolols (used chiefly in conjunction with other solv ents) methyl, ethyl, propyl, and amyl, methyl-amy ether, acetic ether, di-ethyl-ketone, methyl-ethyl keton amyl nitrate and acetate, nitro-benzole, nitro-toluol, ni-
trated oils, glacial acetic acid, camphor dissolved in trated oils,
alcohol, etc.

alcohol, etc.

Some of the above may be called selective solvents, i.e., they dissolve one particular variety of gun-cotton better than others, so that solubility in any given solv No nitro-cotton is entirely soluble in any solvent. The solution, after standing some time, always deposits small amount of' insoluble matter. Therefore, in making collodion solutions, care should be taken to place ion and shock. After standing a few weeks the clear
supernatant liquid may then be decanted off. On a larger scale collodion solutions are filtered under pressure through layers of tightly-packed cotton wool. The state of division is important. When the end in view
is the production of a strong film or thread, it is advisable to use unpulped or only slightly pulped nitrocellulose. In this condition it also dissolves more easily than the finely pulped material.

\section{THE CHAMPAGNE INDUSTRY.}

By Consul J. Martin MILIEr.

During the past five years the consumption of champagne wine in the United States has increased over
35 per cent, or an average of about 7 per cent a year. The United States imported 1,235,880 bottles (quarts) more from the champagne district in 1905 than in 1900 . to the United States, the high tariff operating to keep out the low grades. The United States is now con the amount in customs duties paid into the United States Treasury on account of this champagne, all o which is produced in what may be called the legal $\$ 3,000,000$ a year.

$$
\text { RELATIVE CONSUMPTION OF COUNTRIES. }
$$

The quantity of champagne in quart bottles* ex uring the past six years is as follows:

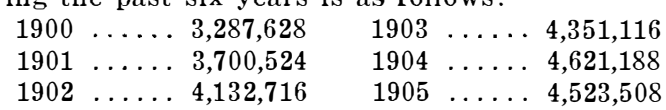

Great Britain imports almost double the amount represented in the figures for the United States, and drinks more champagne than any other nation. The United States ranks second and Russia third as chamUnited States ranks second and Russia third as cham-
pagne-drinking nations. Belgium is the greatest champagne-drinking nations. Belgium is the greatest cham-
pagne-consuming nation in the world per capita, and pagne-consuming nation in the world per capita, and
the Scandinavian States are second in that respect, Norway leading Sweden or. Denmark.

While France is recorded in the government reports as having consumed 9,335,412 quart bottles in 1903 , understood in 1904, and $8,864,947$ in 1905 , it must be nderstood that the greater part of this is the very cheap quality of wine made from the last pressings and the refuse of the champagne grapes that the firstclass houses cannot use in their export trade. In the than one-fourth of these figures represent the champagne, in its true sense, that is consumed in France. QUANTITIES EXPORTED.

The quantity of champagne sold from the Rheims district to all of the countries of the world, including France, for each year since 1900, inclusive, in quart
$1900 \ldots .28,454,436$
$\begin{array}{lll}1901 & \ldots \ldots & 28,055,04 \\ 1902 & \ldots & 28,205,44\end{array}$
1903
$31,859,158$

Of all the champagne that is consumed in the world proximately one-seventh. Japan was about one-third more in 1905 than in 1904. Fifteen years ago the people of Japan used little or no champagne, and shipments were made only for the foreign residents. The exporters here point with pride "Yankees fact that this denotes the progress of the China consumes very little champagne, and there no record of any ever having been sent to Korea. UNIFORM CUSTOMS DUTY.

The tariff on champagne is higher in Brazil ( $\$ 1.44$ a quart) than in any other country. Russia has the and Germany fifth. On March 15, 1906, Russia reduced the tariff from 95 cents to 91 cents a quart. Italy has world ad tariff. Greece is the only country in the the very low tariff of 15 cents per quart. The following table gives the tariff per quart in the several countries, expressed in United States money:

Brazil ........\$1.44 Switzerland $\ldots \ldots \ldots 0.27$

Russia $\ldots \ldots \ldots . .91$ Italy

Germany $\ldots \ldots \quad .57$ Austria-Hungary

Mexico ......... .54 Portugal

Cape Colony .... †.52 Argentin

$\begin{array}{llll}\text { Norway } & \ldots \ldots \ldots & .42 & \text { Chile } \ldots . . \\ \text { Sweden } & \ldots \ldots \ldots & .39 & \text { Venezuela }\end{array}$

Denmark

Great Britain

$$
\begin{array}{ll}
.39 & \text { Venezuela } \\
.12 & \text { India }
\end{array}
$$

Canada

Philippines

.15 Federated Au

$\begin{array}{llll}\text { Philippines } \ldots \ldots & .662-3 & \text { Egypt } \\ \text { Belgium } \ldots \ldots \ldots & .10 & \text { China }\end{array}$

171-2 Turkish Empir public collect an "octroi" tax, however. This is 1 cent per bottle on all consumed in Rheims, and 6 cents at years ago.

Champagne is probably the only commercial com-

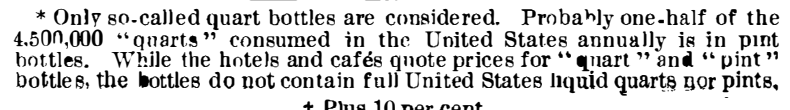

to year, in either the wholesale or the retail price. It is the same this year as it was one year, five years, and ten years ago. The crop of champagne grapes may be much shorter in some years than others, but this does not affect the price of champagne in the least. Another peculiar feature of the champagne trade is is practically what the tariff may be the retail pric champagne at one of the leading hotels in Paris, where there is no duty, will cost about the same as at a similar place in New York or other American city; and the price is practically the same in London, Berlin, St. Petersburg, or Rome, the tariff apparently cutting no figure in establishing the price. Consumers in the
United States should be thankful for the high tariff for the reason that it protects them against inferior qualities of sparkling wine.

\section{INFERIOR GRADES.}

The fourth and fifth pressings of the champagne grapes and the imperfect grapes that are separated by hand from the choice ones are made into a cheap champagne of two or three different grades. name "champagne" on this cheap wine, for it is made name. "champagne" on this cheap wine, for it is made
from champagne material. The great houses sell their last pressings and rejected materials to the smaller houses in the trade. This cheap champagne retails at the lower class of restaurants and public houses in Rheims, Paris, and other cities in France at 1 franc ( 20 cents) up to 2 or 3 francs per pint bottle. It will be seen that the cheapest grade sells for less searkLe brom

t is safe to say that the sparkle in all the cham. pagne shipped from here to the United States is from natural fermentation. Some of the cheaper sparkling wines, sometimes called "champagne," are artificially charged the same as the so-called champagne cider or soda water. This kind of sparkling wine has nothing in common with sparkling champagne except the bubbles. It is easy to detect the artificially prepared wine former dies a way almost immediately, while that of the latter remains for some length of time.

Theie seems to be an impression in the United States that considerable California still wine is sent to France and manufactured into champagne. Further on in this report I explain the law and why it is impossible to use for this purpose any material grown outside the champagne district. I am in receipt of a report from the French government giving the amount of Calinamed, as imported to France during the three years named, as follows: 1903, 63 hectoliters, or about 5,040 1905 , 1904, 151 hectoliters, or about 12,080 quarts, that 48 hectoliters, or about 3,840 quarts. The fact from Tunis and lla of cheap wine come to France champagne industry whatever. The French people are the greatest consumers of cheap wines in the world. It is used more generally than milk in the
United States. Even the little children drink it. The United States. Even the little children drink it. The public schools give it to the pupils. Th
sist upon the daily allowance for wine. AGE DOES NOT IMPROVE.

Much of the champagne sent to the United States from here is three years old, but some of the choicest brands are five years old. Champagne, however, does not improve with age. Owing to the fact that it renot improve wrom three to five years to place champagne on quires from three to five years to place champagne on
the market after the grapes are pressed, it will be seen that vast capital is required by the great houses to that vast capital is required by the great houses to
keep the necessary stock on hand from which to meet keep the necessary stock on hand from which to meet
current demands. The amount of stock constantly on current demands. The amount of stock constantly on
hand in the cellars of the great houses of Rheims and vicinity amounts to about three times the amount that is sold every year. Should there be an entire failure is sold every year. Should there be an entire failure
of the grape crop in any one year there would be of the grape crop in any one year there would be
enough stock on hand to supply the trade without in. terruption.

The quantity of champagne stock on hand during

\begin{tabular}{|c|c|c|}
\hline 1900 & $\begin{array}{c}\ldots 99,019,659\end{array}$ & 1903 \\
\hline 1901 & $100,641,967$ & 1904 \\
\hline 1902 & $113,898,775$ & 1905 \\
\hline
\end{tabular}
the past six years was as follows, the figures repreMANY MILES OF CAVES.

The great caves or cellars are miles in extent, dug out of the solid chalk, from 20 to 100 feet under ground, one under another, without any supports for
the most part. It is under ground in these caves that the most part. It is under ground in these caves that
the champagne is made, and where it is kept after the grapes are pressed, for from three to five years before it can be shipped to the dealers. The caves are com. pletely lighted by electricity. Six of the large firms
have caves that are 8 to 11 miles in extent each. These have caves that are 8 to 11 miles in extent each. These
caves are in reality subterranean passages that almost caves are in reality subterranean passages that almost
rival the catacombs of Rome in extent. They are much greater in the number of miles than the subways or underground railways of New York and London com bined. The champagne caves of Rheims and vicinity are estimated to be fully 150 miles in extent. The sit on which Rheims is located, in the business portion a least, is completely honeycombed underneath with
tunneled caves. The great caves of Pommery and some others are in the environs of Rheims. 